\title{
SINTERING AND CHARACTERIZATION STUDIES OF NiO
}

M. JIMÉNEZ-MELENDO, A. DOMÍNGUEZ-RODRÍGUEZ, R. MÁRQUEZ and J. CASTAING*

Departamento de optica, Facultad de Física, Aptdo. 1065. 41080 Sevilla, Spain

"Laboratoire de Physique des Matériaux, C.N.R.S. Bellevue, F-92195 Meudon Cedex, France

\begin{abstract}
Résumé - Des polycristaux de Ni0 de haute puretê ont été élaborés par frittage avec et sans charge. Ils ont été caractérisés par microscopie optique et électronique. Leur comportement en fluage a été étudié au dessus de $1200^{\circ} \mathrm{C}$.

Abstract - High purity Nio polycrystals have been prepared by hotpressing and by sintering. They were characterized by optical and electron microscopy. Their creep behaviour was studied above $1200^{\circ} \mathrm{C}$.
\end{abstract}

\section{I - INTRODUCTION}

Nickel oxide polycrystals have been prepared with the aim of studying their plastic deformation. For mechanical testing, materials with stabilized microstructure (grain size, porosity, ...) are needed. We have prepared $\mathrm{NiO}$ polycrystals two ways similar to those previously used for $\mathrm{Ni0} / 1 /$ or $\mathrm{Co0} / 2,3,4 /$ and characterized the resulting specimens by microstructural observations and creep testing.

I I - PREPARATION OF POLYCRYSTALS

II-1 - Initial sintering

The starting powder was high purity $\mathrm{NiO}$ provided by Johnson-Matthey (total impurity content below $15 \mathrm{ppm}$ ) with an average particle size of $0.1 \mathrm{\mu m}$. The powder was first cold-pressed in a die under $400 \mathrm{MPa}$. It was then annealed 3 days in air at $1200^{\circ} \mathrm{C}$ on a boat made of $\mathrm{NiO}$ to avoid contamination. The density of the sintered body was $65 \%$ of the theoretical density taken as 6.8 $\mathrm{g} / \mathrm{cm}^{3}$ and the grain size of the order of $1 \mu \mathrm{m}$. Such a material is not appropriate for high temperature mechanical testing and two types of additional treatment were required.

\section{II-2 - Ultra-high temperature sintering}

Since most of the creep tests were to be performed below $1400^{\circ} \mathrm{C}$, sintering treatments between $1500^{\circ} \mathrm{C}$ and $1700^{\circ} \mathrm{C}\left(0.80 \mathrm{TM}\right.$ and $0.88 \mathrm{TM} ; \mathrm{TM}_{\mathrm{M}}=2230 \mathrm{~K}$, melting temperature) were performed in air during 3 days. To avoid contamination, the specimens were separated from the alumina crucible by a bed of $\mathrm{NiO}$. 
II-3 - High temperature compression

The low density sintered bodies were subjected to large creep deformation in order to stabilize their microstructure. The starting specimens, with $12 \times 10$ $\times 10 \mathrm{~mm}$ dimensions, were placed in the compression creep machine and strained at $1150^{\circ} \mathrm{C}<\mathrm{T}<1300^{\circ} \mathrm{C}\left(0.64<\mathrm{T}_{M}<0.71 \mathrm{TM}\right)$ in air by applying stresses between 5 and $24 \mathrm{MPa}$ for 6 to 24 hours. The total strain $\varepsilon$ was between 0.6 and 1.5. For these experimental conditions, the rate controlling mechanism of deformation is diffusional creep $/ 5 \%$.

Specimen were then cut from resulting body for the actual creep tests with stress axis either parallel or perpendicular to the direction of hot-pressing.

\section{III - SPECIMEN CHARACTERIZATION}

We have determined various characteristics of the NiO polycrystals:

(i) The density was deduced from the ratio of weight to volume. The density is known with an accuracy of $0.2 \%$ which is controlled by the size measurements.

(ii) The grain size and morphology were determined from optical and scanning electron micrographs. For that purpose, grain boundaries were chemically etched $\left(\mathrm{H}_{3} \mathrm{PO}_{4}, 15 \mathrm{mn} \text { at } 160^{\circ} \mathrm{C}\right)^{\circ}$ on mechanically polished surfaces.

We have used a semiautomatic image analyser Kontron MOP-30 to average the data on up to 300 grains for each polycrystal. The grain size was taken as the equivalent planar diameter, defined as $d=4$ (grain area)/ $\pi)^{1 / 2}$. We have also determined a form factor, defined as $F=4 \pi$ (grain area)/(grain perimeter) ${ }^{2}$, which gives quantitative information on grain shapes and tentatively made an evaluation of their preferential orientations.

(iii) The presence of dislocations in the grains was investigated either by chemical etch pitting $\left(\mathrm{HNO}_{3}, 20 \mathrm{mn}\right.$ at $\left.105^{\circ} \mathrm{C}\right)$ of fracture surfaces or by transmission electron microscopy of thin foils prepared by mechanical, chemical and ion thinning.

(iv) Mechanical data provided additional characteristics of the materials. Tests were performed in a creep machine described in $/ 6 \%$.

IV - RESULTS AND DISCUSSION

(i) The density of the hot-pressed specimens was always higher than for the sintered ones in spite of the difference in temperatures. Values up to $97 \%$ theoretical density were found after compression at $1300^{\circ} \mathrm{C}(\sigma=20 \mathrm{MPa}, t=$ 12 hours); after sintering between $1600^{\circ} \mathrm{C}$ and $1700^{\circ} \mathrm{C}$, they were never above $88.1 \%$. In another work, a relative density higher than $99.7 \%$ was achieved; this was obtained under stresses much higher than the ones we used $/ 1 /$.

Most of the pores were found at the grain boundaries and especially at triple points; this is analogous to observations made for $\operatorname{coO} / 4 \%$. We did not find any influence on pore placement related to the different preparation techniques.

(ii) A minimum mean grain size of $6.3 \mu \mathrm{m}$ was obtained for polycrystals hot-pressed at $1150^{\circ} \mathrm{C}$ during 12 hours (fig. 1-a). For sintered specimens, the grains were always larger (fig. $1-b$ ) and could reach $20 \mu \mathrm{m}$ at $1700^{\circ} \mathrm{C}$. These grain sizes are similar to those found for CoO in similar conditions $/ 2,4 /$. The shape of the grain size distributions (Fig. 1) are consistent with a lognormal law as often observed $/ 7 /$. However, the polycrystals processed under stress at low temperature showed defective areas which retained roughly the initial grain morphology (Fig. 2). The highest density of these areas was found at $1150^{\circ} \mathrm{C}$ and did not exceed $10^{-2} \mathrm{~cm}^{-2}$. 

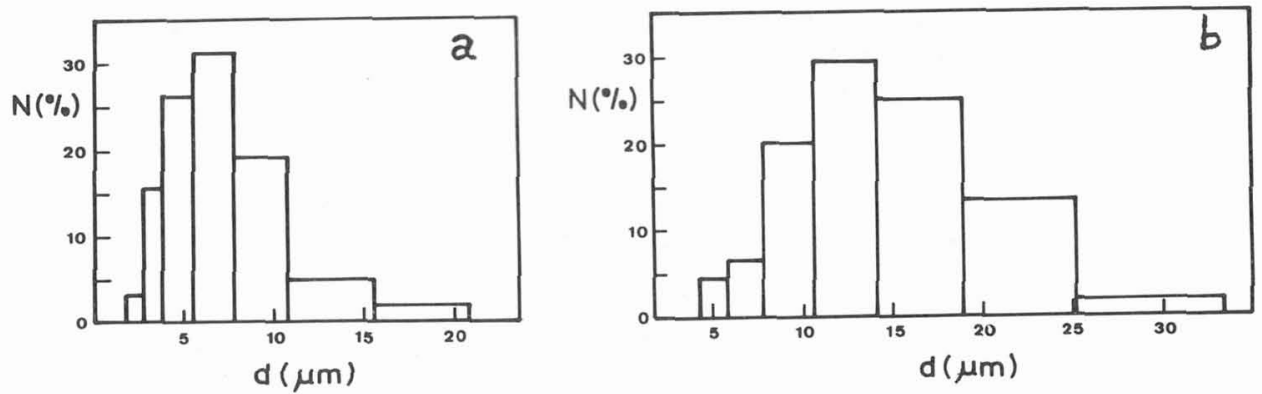

Fig. 1 - Histograms of the grain-size d distribution for polycrystals obtained by: (a) hot-pressing, $T=1150^{\circ} \mathrm{C}, \sigma=16 \mathrm{MPa}, t=12$ hours and $d=6.3 \mu \mathrm{m}$; (b) sintering, $T=1600^{\circ} \mathrm{C}, t=3$ days and $\mathrm{d}=13.4 \mu \mathrm{m}$. The plot shows the percentage $\mathrm{N}$ of grains versus $\mathrm{d}$.

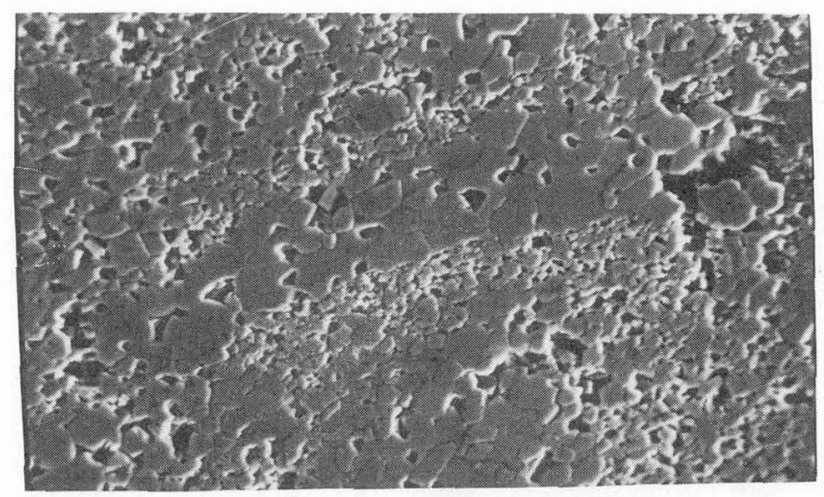

Fig. 2 - Scanning electron micrograph $(X 1300)$ of a hot pressed polycrystal ( $T$ $=1150^{\circ} \mathrm{C}, \sigma=17 \mathrm{MPa}, t=6$ hours) showing a defective area with small grains.

We have insufficient results to make a quantitative study of the kinetics of grain growtin, which is generally found to follow the law :

$$
d^{m}-d_{0}^{m}=k \cdot t \cdot \exp (-Q / k T)
$$

$d, d_{0}=$ grain size at time $t$ and $t=0 ; K=$ constant $; Q=$ activation energy

A value of $m=4$ has been found for alumina $/ 8 /$, but $m=3$, for $M g 0 / 9 /$ and $\mathrm{CoO} / 4 /$, is a more usual observation for porous materials. If we fit our data with $m=3$, we find $d_{0}=1 \mu \mathrm{m}$ and an activation energy of $3.8 \mathrm{eV}$, much larger than the one for $\mathrm{Ni}$ self-diffusion $/ 10 \%$. This is an indication that the rate controlling mechanism for sintering between $1500^{\circ} \mathrm{C}$ and $1700^{\circ} \mathrm{C}$ is the self-diffusion of oxygen, the slowest species in $\mathrm{NiO} / 10 \%$.

The grains generally exhibit equiaxial shapes; the form factors $F$ are larger than 0.7 (Fig. 3), the maximum value for a circle being 1 . For hot-pressed $\mathrm{Ni} 0, \mathrm{~F}$ is not smaller than for sintered materials, a fact that can be related to the mechanism of plastic deformation, to be discussed in a further paper (see also M. Jiménez-Melendo, Tesis Doctoral, Universidad de Sevilla, 1985). 
$X$-ray diffraction was used to reveal the presence of any prefered orientation of the grains. A Philips texture goniometer was used (1). Random orientations were found for sintered polycrystals as well as for hot-pressed ones, in spite of the large uniaxial compression.

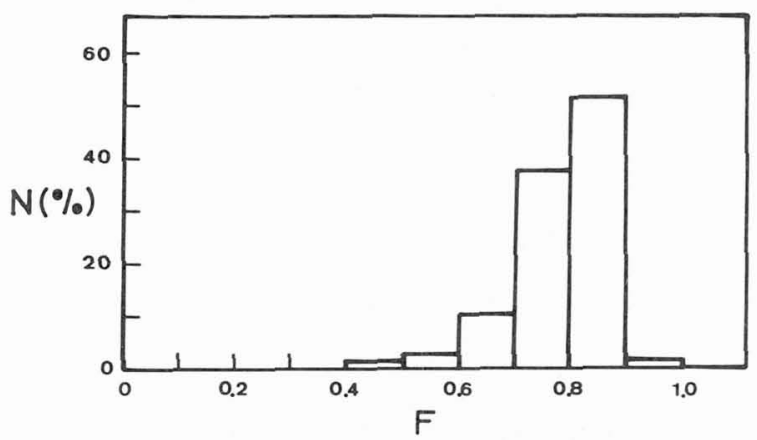

Fig. 3 - Histogram of the form factor $F$ distribution for the polycrystal with grain size depicted in fig $1 \mathrm{~b} ; \mathrm{F}=0.8$

(iii) The presence of high dislocation densities may be expected in polycrystals which have undergone plastic deformation. Fracture surfaces displayed large amounts of (100) cleaved faces (transgranular fracture) where dislocations can be revealed by chemical etch-pitting $/ 11 /$. Pit densities were remarkably low in both types of polycrystals (Fig. 4). TEM observations were also performed; dislocations were observed. Their small density occasionally is an indication that plastic deformation occurs essentially by a dislocationfree mechanism in the conditions used for the preparation of the hot-pressed polycrystals.

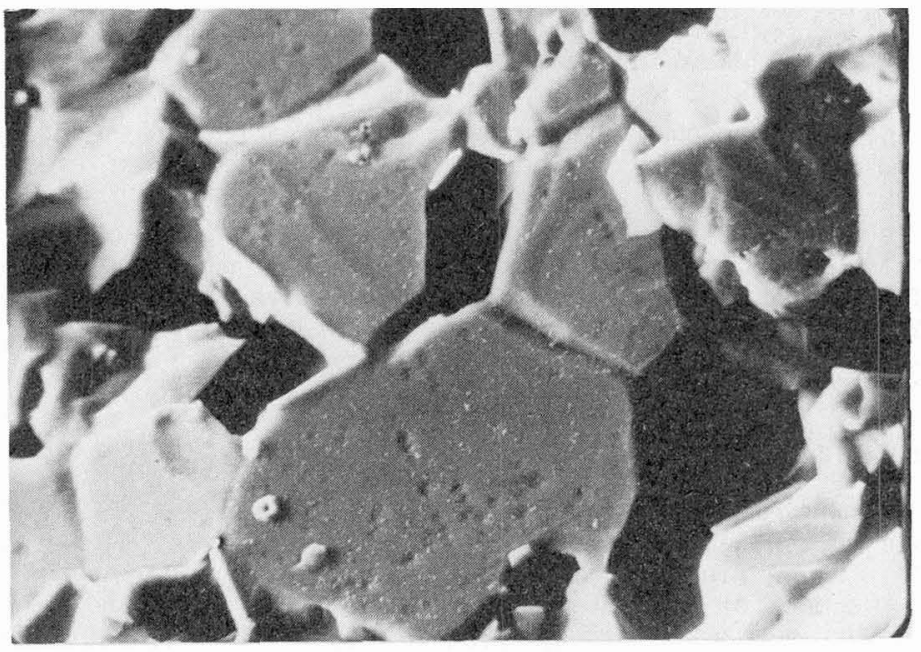

Fig. 4 - Scanning electron micrograph $(x$ 2000) of a sintered specimen ( $T=1700^{\circ} \mathrm{C}, 3$ days) showing $(100)$ cleaved faces on some grains with dislocation etch pits.

(1) O.A. Ruano, CENIM, Madrid, is acknowledged for his help. 
(iv) The aim of our work is the study of high temperature plastic deformation of $\mathrm{NiO}$ polycrystals. We discuss the mechanical data obtained for both kinds of materials. Creep curves are shown in the figure 5. Since the tests are performed at constant load, the stress $\sigma$ decreases at increasing $\varepsilon$ according to $\sigma=\sigma_{0} \exp (-\varepsilon)$ for homogeneous deformations, where $\sigma_{0}$ is the value displayed in fig.5. If $\dot{\varepsilon} \propto$ on, the relation between $\ln \dot{\varepsilon}$ and $\varepsilon$ is linear. The slope of the straight line is equal to $n$; we found values between 1 and 2 , in agreement with stress exponents determined otherwise $/ 5 \%$.

For small $\varepsilon$, transients have been observed (fig.5, curve A) for hot pressed specimens when the creep stress is perpendicular to the one of specimen preparation (see section 2.3). This is probably due to a slight change of the microstructure which cannot be detected by other characterisation techniques.

Such transients were not observed for sintered specimens. Their mechanical data showed a small. scatter for identical $\sigma$ and $T$, the ratio of maximum to minimum $\dot{\varepsilon}$ was 2 , when for hot pressed polycrystals, it could reach 10 . The latter ones generally deformed faster (fig.5) than the former by a factor 5 to 10. These differences in behaviour must very likely be ascribed to the existence of randomly distributed defective areas with small grain-sizes found in hot pressed NiO (fig.2). Although this preparation is easier (low T) and gives high density bodies, this technique is not as valuable as the high $T$ sintering to provide NiO polycrystals for medium $\mathrm{T}$ range creep tests.

Acknowledgements

The authors are indebted to F. Bernier, F. Cumbrera and B. Pellissier for their assistance in the experimental work.

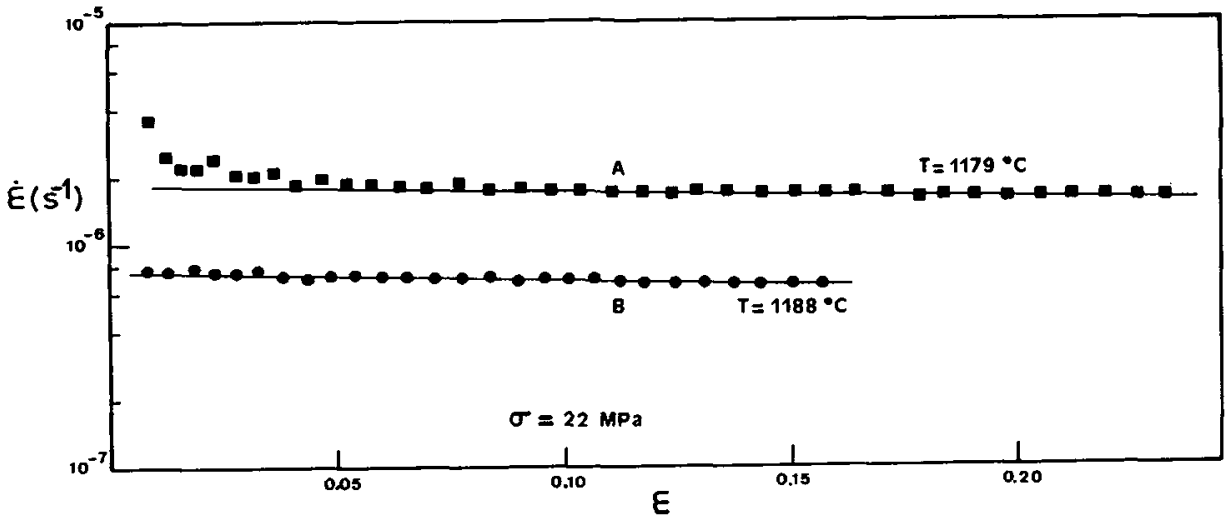

Fig. 5 - Creep curves for polycrystals obtained by (A) hot-pressing, $T=1300^{\circ} \mathrm{C}$, $\sigma=10 \mathrm{MPa}, t=12$ hours with $d=10 \mu \mathrm{m}(\mathrm{B})$ sintering, $T=1500^{\circ} \mathrm{C}, 3$ days with $\mathrm{d}=9 \mu \mathrm{m}$.

\section{References}

T1/Notis, M.R., Urick, P.A. and Spriggs, R.M., in Materials Science Research (edited by G.C. Kuczinsky), vol.6, p.409. Plenum Press, New York, 1973.

/ 2/ Urick, P.A. and Notis, M.R., J. Amer. Ceram. Soc. 56 (1973) 570.

/ 3/ Kumar, P. and Johnson, D.L., J. Amer. Ceram. Soc. 57 (1974) 62.

/ 4/ Kumar, P. and Johnson, D.L., J. Amer. Ceram. Soc. 57 (1974) 65. 
/ 5/ Jimenez-Melendo, M., Cabrera-Cano, J., Dominguez-Rodriguez, A. and Castaing, J., J. Phys. Lett. 44 (1983) L339.

/ 6/ Gervais, H., Pell issier, B. and Castaing, J., Rev. Int. Hautes Tempér. Réfract. 15 (1978) 43.

/ 7/ Kurtz, S.K. and Carpay, F.M.A., J. Appl. Phys. 51 (1980) 5725.

/ 8/ Fridez, J.D., Carry, C. and Mocellin, A., in Advances in Ceramics (edited by W.D. Kingery), vol.10, p. 720. The American Ceramic Society, Ohio, 1984.

/ $9 /$ Crampon, J., Thèse d'Etat, p. 122. Universitê des Sciences et Techniques, Lille, 1983.

/10/ Monty, C., Rad. Effects 74 (1983) 29.

$/ 11 /$ Guiberteau, F., Dominguez-Rodriguez, A., Spendel, M. and Castaing, J., to be published. 